\title{
Carpal tunnel syndrome: Diagnosis and surgical treatment
}

\author{
Faton Morina ${ }^{1}$, Cen Bytyqi ${ }^{1}$, Aziz Mustafa $^{2 *}$, Gentian Morina $^{1}$ \\ ${ }^{1}$ Clinic of Orthopedics, University Clinical Center of Kosova, Prishtina, Kosova \\ ${ }^{2}$ ENT Clinic, University Clinical Center of Kosova, Prishtina, Kosova; \\ *Corresponding Author: aziz_mustafa2000@yahoo.com
}

Received 21 January 2012; revised 18 February 2012; accepted 4 March 2012

\begin{abstract}
Carpal tunnel syndrome (CTS) is a compressive idiopathic neuropathy, most commonly affecting the median nerve in the upper extremity. CTS have high prevalence, with up to $70 \%$ of cases in women aged between 45 and 60 years. Typical manifestations of CTS are numbness of the index and middle fingers, which also become painful and cause the patient to awaken from sleep. In the period from January 2008 to October 2011 at the Orthopedics Clinic of the University of Kosovo, surgery for decompression of the median nerve was performed for 32 patients with CTS. The patients had an average age of 49.1 years. After surgery, $81.25 \%$ of the patients experienced complete improvement, whereas partial improvements were noted in $18.75 \%$ of the patients. This treatment is easy and feasible, has high efficiency, can be performed under local anaesthesia, and confers improvements in terms of return to daily activities, with low risk of complications or relapse.
\end{abstract}

Keywords: Carpal Tunnel Syndrome; Hand Surgery; Local Anesthesia

\section{INTRODUCTION}

Carpal tunnel syndrome (CTS) is a compressive idiopathic neuropathy of the median nerve with common localization in the upper extremity caused by mechanical pressure on the nerve during its passage through the carpal tunnel. The prevalence of CTS in the USA is 1:20 for persons between the ages of 45 and 60 years, with $10 \%$ of sufferers aged less than 30 years [1]. Women account for up to $70 \%$ of cases of CTS. Typical manifestations of this disease are numbness and pain of the index and middle fingers, pain after waking from sleep and, in advanced cases, muscular strength decrease and hypotro- phy of the thenar skin. There are no changes in sensitive innervations because the superficial branch of the median nerve does not pass through the carpal tunnel $[2,3]$. The carpal tunnel is an anatomic compartment at the base of the wrist. Nine flexor tendons and the median nerve pass through the carpal tunnel, which is surrounded on three sides by the carpal bones (which form an arch). The tunnel is wrapped by the ligamentum transversum carpi, which significantly reduces the space for the rigid tunnel to turn in adults, especially during radiocarpal flexion during work or sleep. Diagnosis of CTS is made on the basis of typical symptoms, as well as clinical tests, which include the Phalen [4], Durkan [5], and Tinel [6] tests, as well as electro-diagnostic examinations, which are very reliable because prolonged compression of median nerve damage in the myelin layer results in deteriorations of motor latency and sensitivity [7-10].

Other diseases and conditions that promote and favor the development of CTS include rheumatoid arthritis, hypothyroidism, inflammatory arthritis, fractures and dislocations of the radiocarpal articulation, diabetes, the use of corticosteroids and estrogen, activities of repeated and continuous physical articulation [11], acromegaly, tumors, obesity [12], and genetic factors. Since one of the risk factors for CTS is prolonged or excessive activity while working with the hands, e.g., operating a computer keyboard, this disease is considered a profession-related illness in some countries $[13,14]$.

\section{PATIENTS AND METHODS}

This retrospective study was conducted over a 3-year period. Diagnosis of CTS was based on clinical examination, imaging, and electro-diagnostic parameters. All of the patients underwent electro-diagnostic procedures both before and after surgery. The indications for surgical treatment were: continued symptoms after 6 months of conservative therapy, and signs of muscle damage, determined by electro-diagnostic innervations of median nerve. The most common surgical procedure for patients with CTS is palmary incision, which involves cutting the 
transverse carpal ligament between the thenar and hypothenar skin in the ulnar direction, in order to support the cutaneous palmar branch distally through radial grooves. Using this approach, we get a better view of the ligament and the volume of the tunnel is increased, thereby increasing the possibility for regeneration of the nerve.

\section{RESULTS}

From January 2008 to October 2011, 32 patients with CTS were operated on for release of the median nerve in the tunnel carpal at the Orthopedic Clinic of the University of Kosovo. The goals of the present study were to analyze the outcomes for these patients and to study the effect of surgical treatment.

As shown in Table 1, of the patients in this study, 25 (28.1\%) were female and 7 (21.8\%) male, and the average age was 49.1 years.

Local anesthesia was administered in $90 \%$ of cases; however, regional or general anesthesia was given for relief of pain and to increase precision in seven patients examined by electromyography.

Table 2 shows the side of operation. Twenty patients (62.5\%) were operated on, on the right side, 12 (37.5\%) on the left side, and for three patients (9.3\%), the treatment was bilateral. For only one patient the surgery was repeated after 11 months.

Improvement of symptoms was assessed based on history, clinical examination, and electromyography at 6 and 12 weeks post-surgery. As is shown in Table 3, in 26 (81.25\%) patients, there was improvement of symptoms, while six patients (18.75\%) showed partial improvement. The period of hospitalization was only 1 - 2 days, and post-operative physical therapy after the short splint was continued for 12 weeks.

\section{DISCUSSION}

Current treatment options for patients with CTS include medication, splints, and surgery. Early CTS can be treated with splints in combination with drug therapy and reductions in physical activity.

Local injection of corticosteroids over very short periods can also give good effects. Visser [15] reported that patients who underwent electromioneurography (EMNG) showed moderate changes in nerve parameters; $50 \%$ of patients showed benefits from local treatment with steroids over a period of 15 months. EMNG can also be used for disease diagnosis, although if the problem persists, surgery is the only option that offers definitive relief $[16,17]$. Decompression of the carpal tunnel is a highly effective surgical method in that it initially relieves night pain symptoms and subsequently alleviates the other symptoms of CTS [18]. This procedure is recommended in the USA when the symptoms of disease
Table 1. Demographic profile of the patients.

\begin{tabular}{ccc}
\hline Gender & $\mathbf{N}$ & $\mathbf{\%}$ \\
\hline Male & 7 & 21.8 \\
Female & 25 & 78.1 \\
Total & $\mathbf{3 2}$ & $\mathbf{1 0 0}$ \\
\hline
\end{tabular}

Table 2. Patients with CTS operated on in relation to side affected.

\begin{tabular}{ccccccc}
\hline Year & $\mathbf{2 0 0 8}$ & $\mathbf{2 0 0 9}$ & $\mathbf{2 0 1 0}$ & $\mathbf{2 0 1 1}$ & Total & $\mathbf{\%}$ \\
\hline Right & 3 & 7 & 4 & 6 & 20 & 62.5 \\
Left & 5 & 4 & 2 & 1 & 12 & 37.5 \\
Total & $\mathbf{8}$ & $\mathbf{1 1}$ & $\mathbf{6}$ & $\mathbf{7}$ & $\mathbf{3 2}$ & $\mathbf{1 0 0}$ \\
\hline
\end{tabular}

Table 3. Outcomes of surgery for CTS.

\begin{tabular}{ccc}
\hline Outcome & N & \% \\
\hline Complete recovery & 26 & 81.2 \\
Partial recovery & 6 & 18.7 \\
Total & $\mathbf{3 2}$ & $\mathbf{1 0 0}$ \\
\hline
\end{tabular}

continue for 6 months after the start of conservative treatment. Incision of the transverse carpal ligament enables a moderate increase in the volume of the carpal tunnel, thereby eliminating nerve compression and facilitating rehabilitation. Open surgery is the method of choice for many surgeons because it allows full inspection of the carpal tunnel and its contents. In the majority of cases, local anesthesia in combination with premedicaltion is used. This limits the need for postoperative analgesia and sedation. The wounds are sutured in one layer with vicryl stitches [19]. The precision of the surgical procedure prevents injury to the median nerve and limits the possibility of relapse.

\section{CONCLUSION}

Surgical release of the median nerve in the carpal tunnel is feasible and efficient, can be performed under local anesthesia, and confers improvements in terms of return to daily activities and the alleviation of numbness and pain. The patient quickly returns to daily activities and the risks for complications and relapse are low.

\section{REFERENCES}

[1] Tanaka, S., Wild, D.K., Seligman, P.J., Behrens, V., Cameron, L. and Putz-Anderson, V. (1994) The US prevalence of self-reported carpal tunnel syndrome: 1988 national health interview survey data. American Journal of Public Health, 84, 1846-1848. doi:10.2105/AJPH.84.11.1846

[2] DaSilva, M.F., Moore, D.C., Weiss, A.P., Akelman, E. and Sikirica, M. (1996) Anatomy of the palmar cutaneous branch of the median nerve: Clinical significance. Jour- 
nal of Hand Surgery, 21, 639-643. doi:10.1016/S0363-5023(96)80018-9

[3] Lanz, U. (1977) Anatomic variations of the median nerve in the carpal tunnel. Journal of Hand Surgery, 2, 44-53.

[4] Phalen, G.S. (1966) The carpal tunnel syndrome: Seventeen years' experience in diagnosis and treatment of the six hundred fifty-four hands. Journal of Bone and Joint Surgery, 48, 211-228.

[5] Durkan, J.A. (2001) A new diagnostic test for carpal syndrome. Journal of Bone and Joint Surgery, 73, 535-538.

[6] Kuschner, S.H., Ebramzadeh, E., Johnson, D., Brien, W.W. and Sherman, R. (1992) Tinel's sign and Phalen's test in carpal tunnel syndrome. Orthopedics, 15, 1297-1302.

[7] Aulisa, L., Tamburrelli, F., Padua, R., Romanini, E., Lo Monaco, M. and Padua, L. (1998) Carpal tunnel syndrome: Indication for surgical treatment based on electrophysiologic study. Journal of Hand Surgery, 23, 687-689. doi:10.1016/S0363-5023(98)80056-7

[8] Gubdberg, A.B. (1983) Carpal tunnel decompression in spite of normal electro-myography. Journal of Hand Surgery, 8, 342-349.

[9] Braun, R.M. and Jackson, W.J. (1994) Electrical studies as a prognostic factor in the surgical treatment of carpal tunnel syndrome. Journal of Hand Surgery, 19, 893-900. doi:10.1016/0363-5023(94)90086-8

[10] Jablecki, C.K., Andary, M.T., So, Y.T., Wilkins, D.E. and Williams, F.H. (1993) Literature review of the usefulness of nerve conduction studies and electromyography for the evaluation of patients with carpal tunnel syndrome. AAEM Quality Assurance Committee. Muscle \& Nerve, 16, 13921414. doi:10.1002/mus.880161220

[11] Katz, J.N. and Simmons, B.P. (2002) Carpal Tunnel Syndrome. New England Journal of Medicine, 346, 1807-1812. doi:10.1056/NEJMcp013018

[12] Werner, R.A., Albers, J.W., Franzblau, A. and Armstrong, T.J. (1994) The relationship between body mass index and the diagnosis of carpal tunnel syndrome. Muscle Nerve, 179, 632-636. doi:10.1002/mus.880170610

[13] Higgs, P.E., Edwards, D.F., Martin, D.S. and Weeks, P.M. (1995) Carpal tunnel surgery outcomes in workers: Effect of workers' compensation status. Journal of Hand Surgery, 20, 354-360. doi:10.1016/S0363-5023(05)80086-3

[14] Higgs, P.E., Edwards, D.F., Martin, D.S. and Weeks, P.M. (1997) Relation of preoperative nerve-conduction values to outcome in workers with surgically treated carpal tunnel syndrome. Journal of Hand Surgery, 22, 216-221. doi:10.1016/S0363-5023(97)80154-2

[15] Visser, L.H., Ngo, Q., Groeneweg, S.J. and Brekelmans, G. (2011) Long term effect of local corticosteroid injection for carpal tunnel syndrome. A relation with electrodiagnostic severity. Clinical Neurophysiology, 28 September (Epub ahead of print).

[16] Weiss, A.P., Sachar, K. and Gendreau, M. (1994) Conservative management of carpal tunnel syndrome: A reexamination of steroid injection and splinting. Journal of Hand Surgery, 19, 410-445. doi:10.1016/0363-5023(94)90054-X

[17] Katz, J.N., Keller, R.B., Simmons, B.P., Rogers, W.D., Bessette, L., Fossel, A.H. and Mooney, N.A. (1998) Maine Carpal Tunnel Study: Outcomes of operative and nonoperative therapy for carpal tunnel syndrome in a community-based cohort. Journal of Hand Surgery, 23, 697-710. doi:10.1016/S0363-5023(98)80058-0

[18] Lozanko-Calderon, S., Paiva, A. and Ring, D. (2008) Patient satisfaction after open carpal tunnel release correlates with depression. Journal of Hand Surgery, 33, 303-307. doi:10.1016/j.jhsa.2007.11.025

[19] Theophold, C., Potter, S., Dempsey, M. and O'Shaughnessy, M. (2011) A randomized controlled trial of absorbable versus non absorbable sutures for skin closure after open carpal tunnel release. Journal of Hand Surgery, 10 October (Epub ahead of print). 